\title{
Analysis of Solar Energy Potential and Optimal Panel Tilt Angle in THe Area of THE City of SARajevo
}

\author{
Berin Djikic, Halima Hadziahmetovic, Hamza Cerimovic, \\ Ismira Ahmovic \& Rejhana Blazevic
}
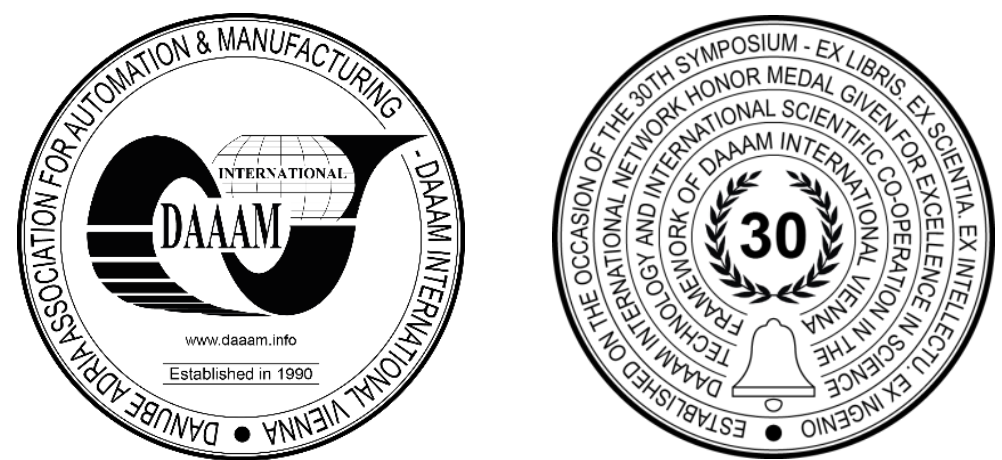

This Publication has to be referred as: Djikic, B[erin]; Hadziahmetovic, H[alima]; Cerimovic, H[amza]; Ahmovic, I[smira] \& Blazevic, R[ejhana] (2019). Analysis of Solar Energy Potential and Optimal Panel Tilt Angle in the Area of the City of Sarajevo, Proceedings of the 30th DAAAM International Symposium, pp.0232-0239, B. Katalinic (Ed.), Published by DAAAM International, ISBN 978-3-902734-22-8, ISSN 1726-9679, Vienna, Austria

DOI: $10.2507 / 30$ th.daaam.proceedings.030

\begin{abstract}
One of the major problems the city of Sarajevo is currently facing is the fact that in winter months the atmosphere is very polluted, mainly because of enormous usage of fossil fuels, primarily for heating. The other issue is the fact that it is extremely energy dependent, only a small portion of it's energy needs is currently produced within the area of the city. These are the two main reasons for the analysis of the solar energy potential in Sarajevo. This paper focuses on analysing the available solar irradiance data obtained from several sources and on providing the exact mathematical method of the analysis, as well as on the results themselves. Furthermore, it also focuses on the effect of the surface tilt angle on the overall amount of the solar irradiance received by the tilted surface. After analysing and processing al the data, a more precise assessment of solar energy potential and the effect of the tilt angle on the overall irradiance received by the tilted surface in Sarajevo is given, as well as the guidelines for further research.
\end{abstract}

Keywords: renewable energy sources; solar irradiance; solar radiation; optimal surface tilt angle.

\section{Introduction}

The city of Sarajevo, and the surrounding areas, are these days faced with two major issues regarding its energy situation. Firstly, it is very dependent on energy imports from other areas of Bosnia and Herzegovina, or even abroad. Currently, in the area of the city, there are only three electric (one hydroelectric and two solar) power plants with a combined installed power of only 7,023 MW [1]. The other issue is heavy air pollution in the city during the winter period. One of the reasons is that many homes are heated using coal and wood biomass. Even the city's district heating system uses natural gas and/or heating oil for producing heat [2]. Even though some of these energy sources are considered as renewable, they all release dangerous gasses (primarily $\mathrm{CO}_{2}$ and $\mathrm{CO}$ ) and also some of them release ash particles, as well as $\mathrm{NO}_{\mathrm{X}}$, and $\mathrm{SO}_{2}$. All of this contributes to very high air pollution in the city during the winter [3]. There are many applications of solar energy which could solve or at least diminish these problems. The solar energy can be used to produce electricity, heat water and homes, also, the development of thermal energy storage technology suggests that some of the unused solar energy could be stored and used later, when needed [4]. The paper analyses and processes solar irradiance data for the period from 2005 to 2017 for the area of the city of Sarajevo. The data is obtained from three different sources, NASA POWER [5], Copernicus Atmosphere Monitoring Service (CAMS) [7] and National Oceanic 
and Atmospheric Administration (NOAA) [6]. The input data used for this analysis are: Global horizontal irradiance (NASA POWER and CAMS), Magnetic declination (NOAA) and Surface reflectance factor (NASA POWER). After analysing and processing the input data a more accurate assessment of the solar energy potential in the area of the city of Sarajevo was given, especially focusing on the effect of the surface tilt angle on the total irradiance it receives.

In the EU, the total installed solar capacity in 2008 was $10505 \mathrm{MW}$ and it rose to $108854 \mathrm{MW}$ in 2017 which is an increase of $936 \%$ in just 10 years [8]. Bosnia and Herzegovina has a lot slower increase in usage of renewable energy sources than the EU, with an increase of only 12,6\% compared to the EUs' 105,5\% from 2008 to 2017 [8]. In 2009 Bosnia and Herzegovina was getting $34 \%$ of its entire yearly energy usage from renewable sources and the plan is for that number to rise to $40 \%$ by 2020 [9]. However, there is an increase in solar energy utilisation from $0 \mathrm{MW}$ installed capacity in 2012 to $12 \mathrm{MW}$ in 2017 [8]. In 2017, 7\% of Germany's electricity produced came from solar energy [21], while it is planed that only $0,27 \%$ of electricity produced in Bosnia and Herzegovina from renewable energy sources in 2020 should come from solar energy. Furthermore, only 2,46\% of governmental subsidies for renewable energy application until 2020 have been awarded to solar energy usage [9]. As well as comparing the current and planned solar energy usage in Bosnia and Herzegovina and the EU, it would be also interesting to compare the amounts of solar Irradiance received by a horizontal surface. The two most interesting countries in the EU, to be compared with Sarajevo and Bosnia and Herzegovina are Germany and Spain, because they are investing heavily in the solar energy usage. In the south of Germany (the majority of its solar energy harvesting facilities are located in the south) the horizontal irradiance is around $1150 \mathrm{kWh} / \mathrm{m}^{2}$ and in Spain it ranges from $1800 \mathrm{kWh} / \mathrm{m}^{2}$ in the south to $1300 \mathrm{kWh} / \mathrm{m}^{2}$ in the north [20].

Since, there is a clear disproportion between the usage of solar energy in the EU and in Bosnia and Herzegovina, there is a need to examine the solar energy potential in the country in order to better understand the possibility of solar energy utilisation in different parts of the country and to guide future investments in this type of renewable energy. So, even though the purpose of the paper is not to define nor to guide future development of the energy sector in the area of the city of Sarajevo, it shows the area's solar energy potential and reviews the possibility of replacing the traditional (dirty) energy sources, with a new, clean and renewable source, as well as the increase in the city's energy independence. This paper, alongside the previous analysis of wind energy potential [10], aims to complete the knowledge of renewable energy potential in the area of the city of Sarajevo.

\section{Analysis and preparation of data for further calculations}

This paper analyses and processes data obtained from three different sources related to the annual irradiance in the city of Sarajevo, and the effect of solar panel or collector positioning on the total amount of irradiance. Figure 1 shows the results of the Monthly Global Horizontal Irradiance (GHI) data for the period from 2005 to 2017 was obtained from two different sources NASA POWER and CAMS [5], [7]. The data was taken for the site with the Longitude $18^{\circ} 25^{\prime} 22^{\prime}$ ', Latitude $43^{\circ} 52^{\prime} 04^{\prime \prime}$ ' and altitude $630 \mathrm{~m}$. From these values, using the arithmetic mean method, the average GHI for every month was calculated independently for both sets of data. Afterwards, since the two sets of data did not yield the same results, the values for each month from both sets of data were averaged and used in later calculations, Figure 2.

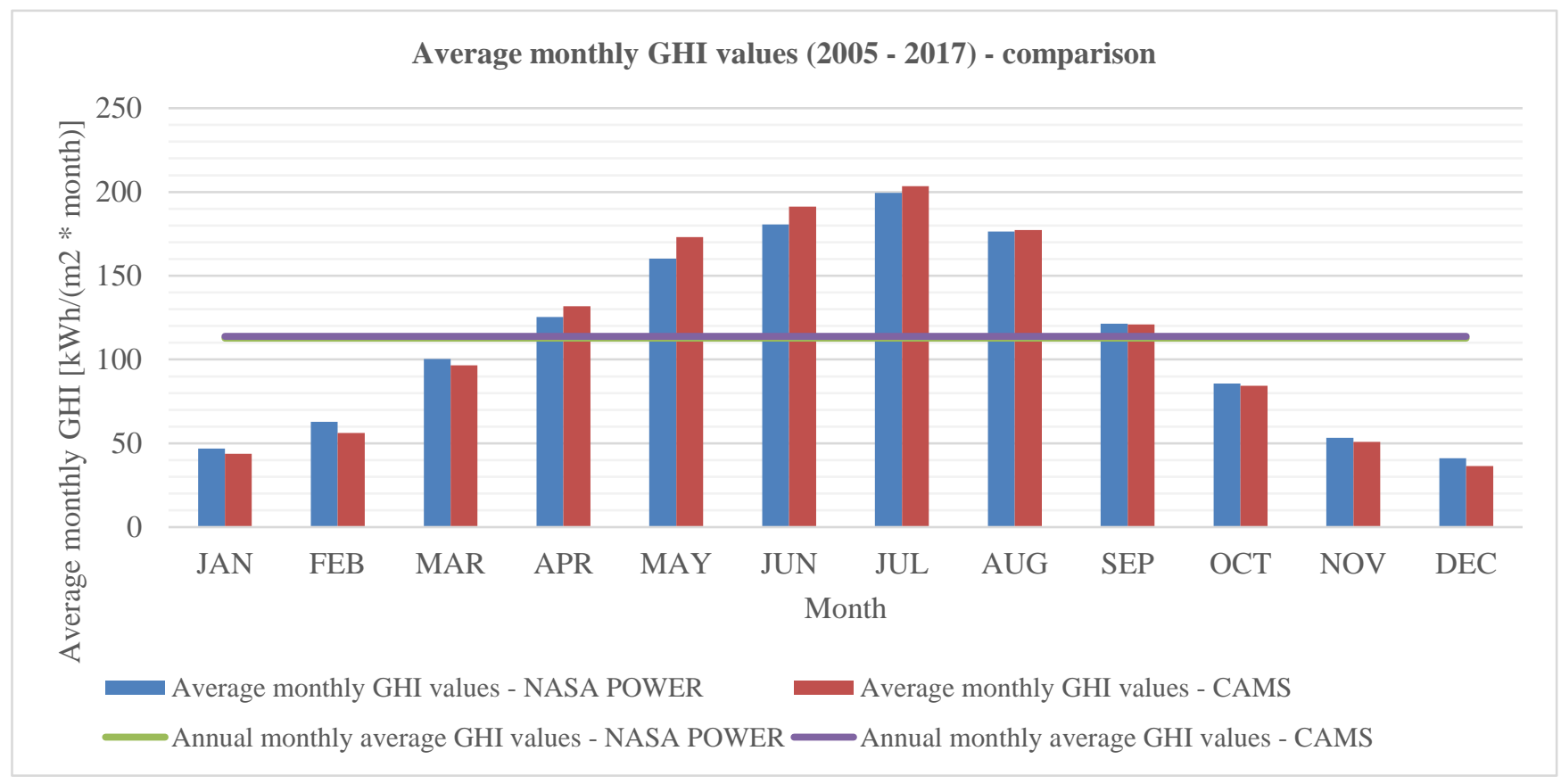

Fig. 1. Comparison of average monthly GHI values obtained from NASA POWER and CMAS for the period from 2005 to 2017 


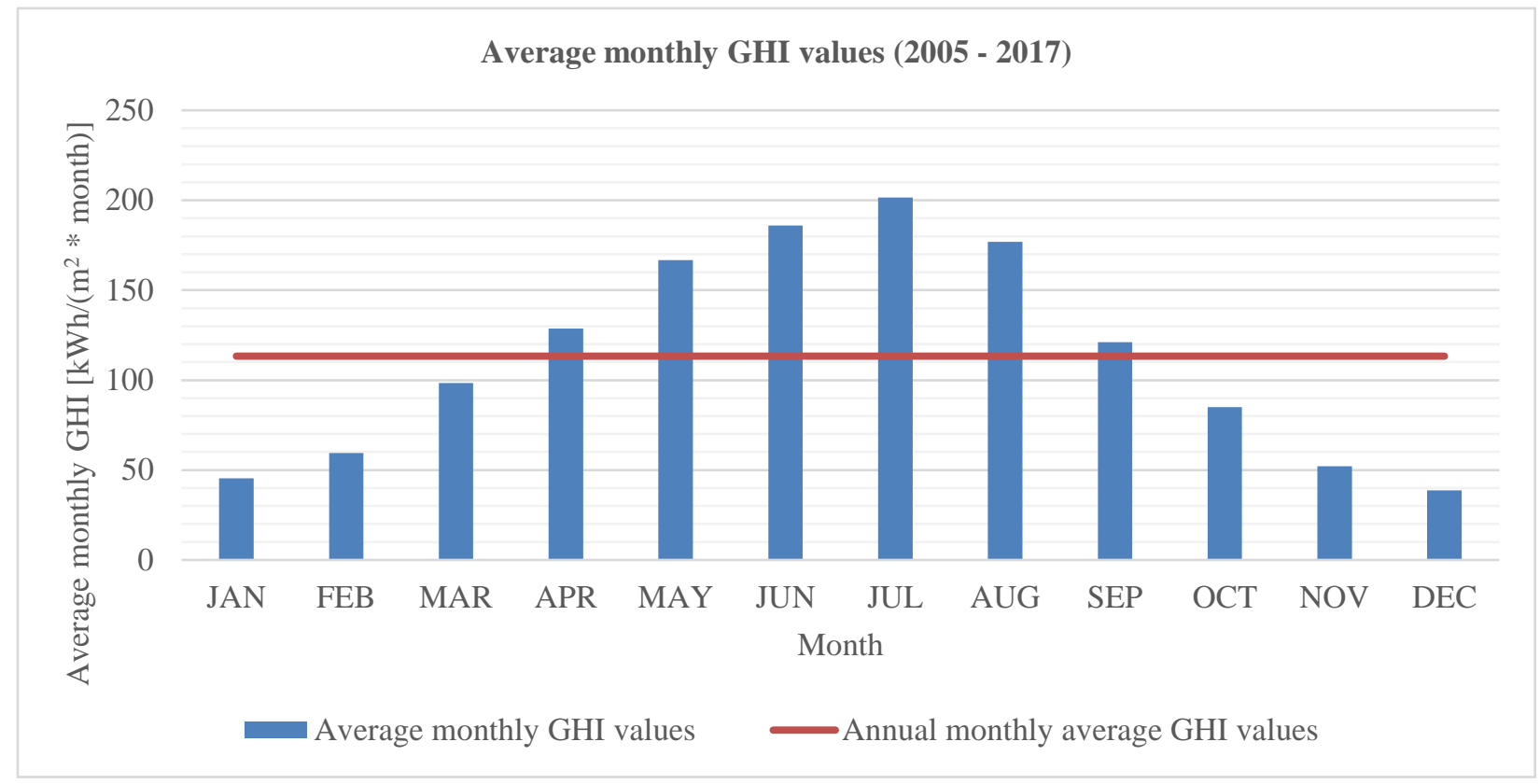

Fig. 2. Average monthly GHI values used in later calculations

In order to correctly calculate the optimal tilt angle and yearly irradiance on a tilted surface the average monthly data needs to be converted into average hourly data for each day of the year. This is a two-step process, firstly the average monthly GHI value for each month is converted into the average daily GHI using the Sunshine Hours Mean Method (SHMM) [11] and later these data are converted into average hourly GHI data using the Collares-Pereira and Rabl model [12]. SSHM takes the average monthly GHI and calculates the daily GHI according to the number of sunshine hours (hours of daylight) in that day. The number of sunshine hours per day and subsequently the average daily values are calculated in the following way [11], [13]:

$$
\delta=23,45^{\circ} \cdot \sin \left[\frac{360}{365}(284+d)\right]
$$

where $\delta$ is Sun's declination angle and $d$ is number of a day in a year,

$$
\omega_{s s}=\cos ^{-1}(-\tan \phi \tan \delta)
$$

where $\omega_{s s}$ is sunset hour angle (in radians) and $\varphi$ is latitude of the location,

$$
S S H=\frac{2 \omega_{S S}}{15},
$$

where $S S H$ is sunshine hours,

$$
H_{h}=\left(G H I_{m} \cdot \sum_{i=1}^{n} \omega_{s s, i}\right) \cdot\left(\omega_{s s, d}\right)^{-1},
$$

where $H_{h}$ is daily GHI value, $G H I_{m}$ is monthly GHI value, $n$ is number of days in a month the values are calculated for, $\omega_{s s, d}$ is sunset hour angle value for a specific day the values are calculated for.

All the values mentioned in (1), (2), (3) and (4) need to be calculated individually for every day in a year. The reason for making such detailed calculations is the fact that the earth is in constant motion in relation to the sun, and since the irradiance values depend on the relative position between the earth and the sun, having more detailed data increases the accuracy of the results. Daily GHI values are later converted into hourly GHI values using the model developed by Collares-Pereira and Rabl [12]. In order to do the required calculations True/Apparent Solar Time (AST) needs to be defined and calculated [15]. AST is given by the daily apparent motion of the true, or observed, sun. It is based on the apparent solar day, which is the interval between two successive returns of the sun to the local meridian.

$$
A S T=L S T+E O T+\left(4 \frac{\min }{\text { degree }}[(L S M T-L O D)]\right),
$$


where $L S T$ is local standard time, EOT is equation of time, LSMT is standard meridian for the local time zone and $L O D$ is longitude of the location.

$$
\begin{aligned}
& L S M T=15^{\circ} \cdot \text { Time zone in GMT, } \\
& E o T=9,87 \sin (2 B)-7,53 \cos (B)-1,5 \sin (B), \\
& B=\frac{360^{\circ}}{365}(d-81) .
\end{aligned}
$$

AST in (5) is given in minutes, so it needs to be converted to hours in order to proceed with further calculations. Hour angle needs to be calculated next [15]. It is the angle between the meridian parallel to sun rays and the meridian containing the observer.

Hour angle should be calculated according to the following:

$$
\omega=15^{\circ} \cdot(A S T-12)
$$

and $r_{h}$ is conversion factor:

$$
r_{h}=I_{h} / H_{h}
$$

where $I_{h}$ is hourly GHI value.

$$
\begin{aligned}
& r_{h}\left(\omega, \omega_{s}\right)=\frac{\pi}{24}(a+b \cos \omega) \frac{\cos \omega-\cos \omega_{s}}{\sin \omega_{s}-\omega_{s} \cos \omega_{s}} \\
& a=0,409+0,5016 \sin \left(\omega_{s}-1,047\right) \\
& b=0,6609-0,4767 \sin \left(\omega_{s}-1,047\right) .
\end{aligned}
$$

All angular values in (11), (12) and (13) are in radians. After calculating the hourly GHI values using (10) and (11) these values need to be decomposed into hourly Beam Irradiance $\left(I_{b}\right)$ and hourly Diffuse Horizontal Irradiance $\left(I_{d}\right)$.

\section{Analysis of solar irradiance components}

Solar radiation coming to the surface of the earth can be decomposed into two types of radiation: beam radiation and diffuse radiation. Beam radiation represents the radiation received from the sun without being scattered by the atmosphere. Diffuse radiation is the radiation received from the sun after its direction has been changed by scattering by the atmosphere. Irradiance is the ratio at which the radiant energy is incident on a surface (horizontal and tilted) per unit area of surface [14].

Since the only available irradiance data is hourly GHI, it is necessary to decompose it into hourly $I_{b}$ and hourly $I_{d}$. It is done using the Reindl-2 model. It uses the clearness index $\left(k_{t}\right)$ to estimate the diffuse fraction $\left(k_{d}\right)$ [16]:

$$
k_{t}=I_{h} / I_{0 h}
$$

where $k_{t}$ is clearness index and $I_{o h}$ is horizontal extra-terrestrial irradiance.

$I_{0 h}$ needs to be calculated for every day in the year and is dependent on the value of the eccentric anomaly of the earth in its orbit around the sun $(E)$ and the current sun's zenith angle $\left(\vartheta_{z}\right)$ [17]. For the calculation of the mean anomaly $(M)$ an approximation that the earth is in Perihelion every $1^{\text {st }}$ of January at midnight is made. After calculating the mean anomaly [18], the eccentric anomaly can be calculated [19]:

$$
M(t)=n\left(t-T_{0}\right)
$$

where $n$ is mean angular motion, $t$ is desired time and $T_{0}$ is Perihelion passing time.

Mean angular motion can be determined by:

$$
n=\sqrt{\frac{\mu}{a^{3}}}
$$


where $\mu$ is sun's gravitational constant and $a$ is earth's orbit semi-major axis.

The value of the eccentric anomaly of the earth in its orbit around the sun:

$$
E=M+e \sin M+e^{2} \sin M \cos M+\frac{1}{2} e^{3} \sin M\left(3 \cos ^{2} M-1\right),
$$

where e is earth's orbit eccentricity.

Sun's zenith angle is a complementary angle to the solar elevation angle $(\alpha)$. $\alpha$ and the reciprocal of the square of the earth radius vector $\left(r_{e}\right)$ are calculated the following way [13], [17]:

$$
\begin{aligned}
& \alpha=\sin ^{-1}(\sin \delta \sin \varphi+\cos \delta \cos \omega \cos \varphi), \\
& \theta_{z}=90^{\circ}-\alpha \\
& r_{e}=1,00011+0,034221 \cos E+1,28 \cdot 10^{-3} \sin E+7,19 \cdot 10^{-4} \cos 2 E+7,7 \cdot 10^{-5} \sin 2 E .
\end{aligned}
$$

All of the previous values need to be calculated for each hour of the year. Horizontal extra-terrestrial irradiance is calculated afterwards [17] and after it the clearness index can be calculated for each hour of the year using (14):

$$
I_{0 h}=1367 r_{e} \cos \theta_{z}
$$

The Reindl-2 model next defines the diffuse fraction in two ways [16]:

$$
k_{d}=I_{d} / I_{h}
$$

where $k_{d}$ is diffuse fraction and $I_{d}$ is horizontal diffuse irradiance.

$$
\begin{aligned}
& k_{d}=1,02-0,254 k_{t}+0,0123 \cos \theta_{z} \text { for } k_{t} \leq 0,3 \\
& k_{d}=1,4-1,749 k_{t}+0,177 \cos \theta_{z} \text { for } 0,3<k_{t}<0,78, \\
& k_{d}=0,486 k_{t}-0,182 \cos \theta_{z} \text { for } k_{t} \geq 0,78
\end{aligned}
$$

Now the $I_{d}$ is calculated using (22) and then the $I_{b}$ can be calculated as well using the following equation:

$$
I_{b}=I_{h}-I_{d}
$$

After decomposing the solar irradiance data into its integral parts, it is possible to analyse the effect of surface positioning on the total irradiance received by the surface $\left(I_{T}\right)$.

\section{Total solar irradiance on the tilted surface}

There are two important angles that affect the amount of solar irradiance the tilted surface receives, surface azimuth angle $\left(\gamma_{s}\right)$ and the surface tilt angle (b). This paper is not focused on the effects of changing surface azimuth angle, only on the effects of the surface tilt angle. So, it is assumed that the surface is directly facing the equator, that means that it should be positioned facing the South. The compass south is not the true south, since it is affected by the earth's magnetic declination and thus it should be adjusted. According to the data taken from [6] the magnetic declination in Sarajevo is $4,48^{\circ} \mathrm{E}$, so the surface azimuth angle should be $175,52^{\circ}$, Figure 3 . 


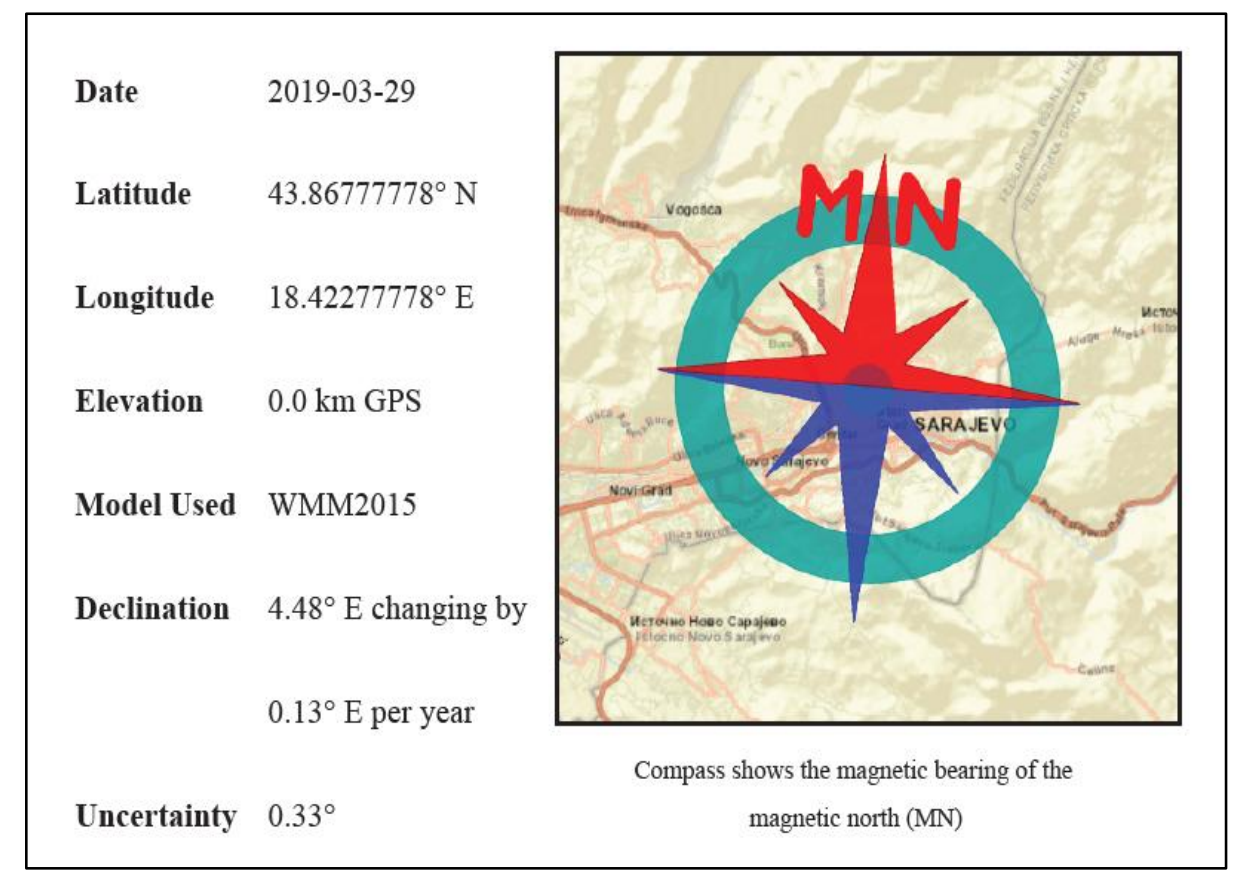

Fig. 3. Magnetic declination in Sarajevo [6]

The total radiation coming to the tilted surface can be decomposed into three components: beam radiation, diffuse radiation and reflected radiation. The total irradiance on a tilted surface can be calculated using the following formula [14]:

$$
I_{T}=I_{b} \frac{\cos \theta}{\cos \theta_{z}}+I_{d} \frac{1+\cos \beta}{2}+I_{h} \rho \frac{1-\cos \beta}{2},
$$

where $I_{T}$ is total hourly irradiance on a tilted surface, $\theta$ is surface incidence angle and $\rho$ is surface reflectance factor.

The surface incidence angle is the angle between the solar beam and the line perpendicular to the surface and is calculated the following way [14]:

$$
\cos \theta=\sin (\phi-\beta) \sin \delta+\cos (\phi-\beta) \cos \delta \cos \omega
$$

Figure 4 shows the results of the surface reflectance factor have been acquired from NASA POWER [5]. These values depend on the type of ground surrounding the site where the panels are located.

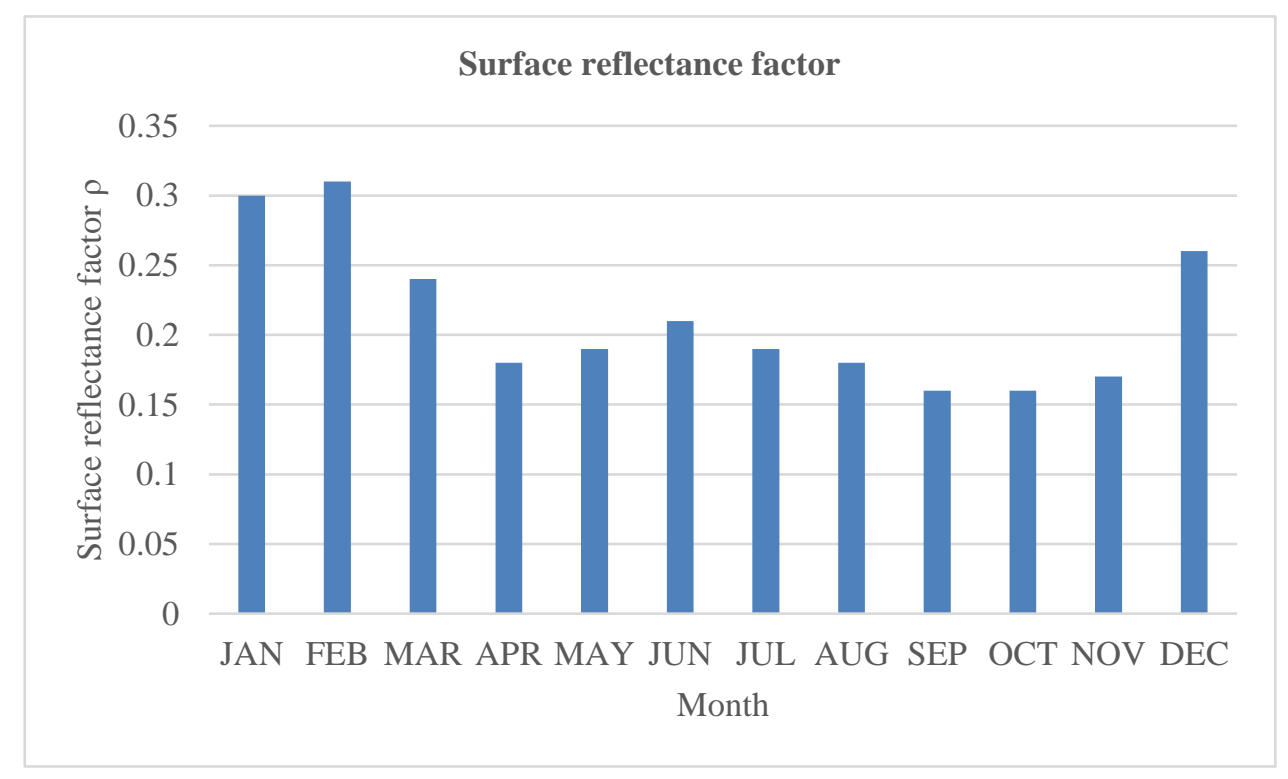

Fig. 4. Surface reflectance factor values for Sarajevo [5] 


\section{Analysis of results}

The calculations mentioned in the paragraphs above have been used to calculate the optimal panel tilt angle and the total yearly Irradiance on a tilted surface. The procedure involved making over 200000 calculations in order to get the definitive results. The results show the optimal surface tilt angle and the total monthly irradiance for every month of the year. Figure 5 shows the results monthly irradiance values on an optimally tilted surface and optimal tilt angle values.

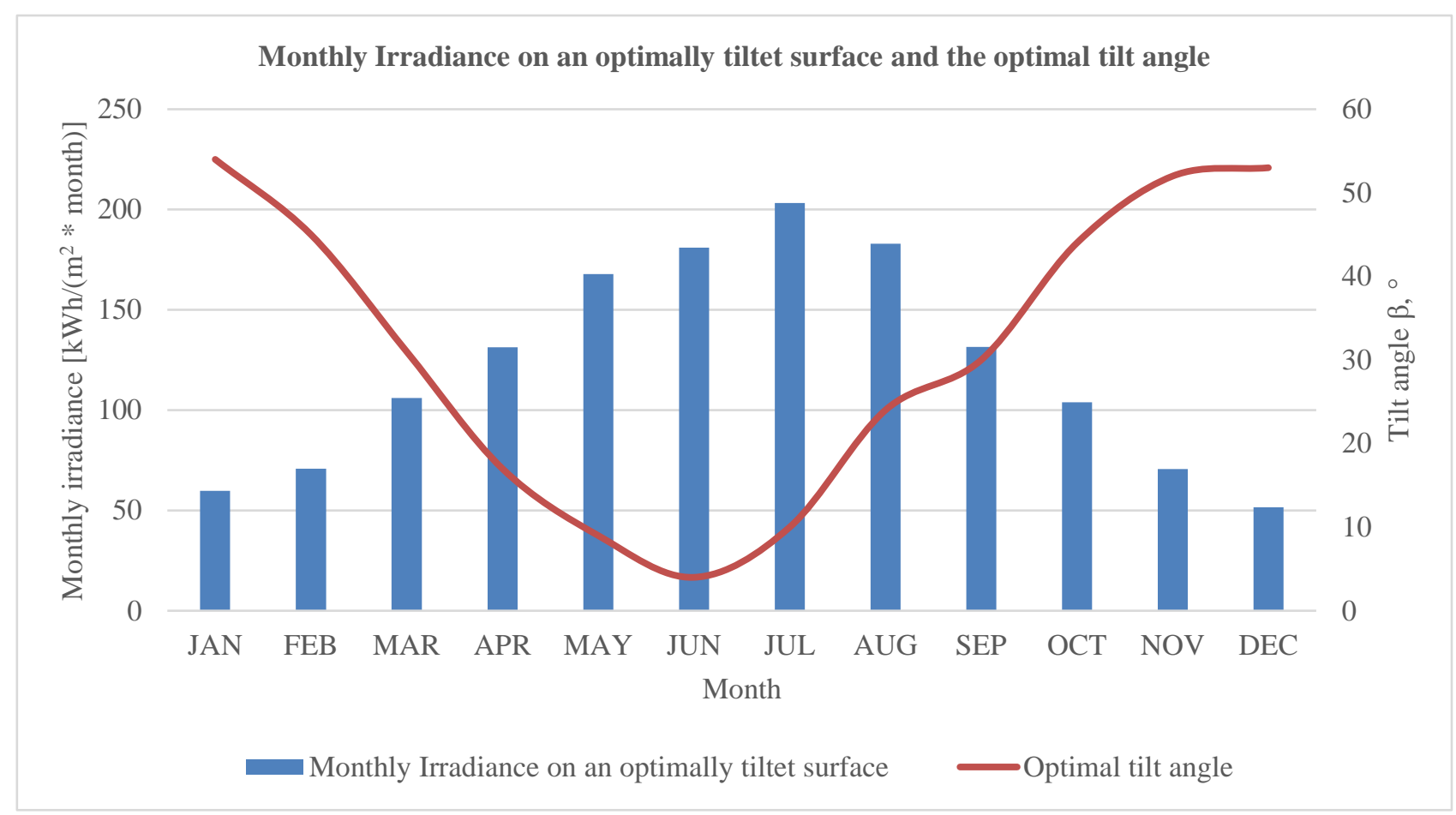

Fig. 5. Calculated monthly irradiance values on an optimally tilted surface and optimal tilt angle values

It is also calculated that the optimal fixed tilt angle for the entire year is $24^{\circ}$ and the relative solar energy loss, compared to the case when the optimal monthly tilt angle is used, is only $2,51 \%$. Also, it is noted that if the surface is tilted at the $33^{\circ}$ (the tilt angle for commercial solar panels in the area varies from $30^{\circ}$ to $37^{\circ}$ ) angle for the entire year the relative solar energy loss is $3,24 \%$. It should also be considered that these results were calculated using some mathematical models which make certain approximations, thus these values could differ from the real measured values, when they become available.

\section{Conclusion}

The results have shown that there is a decent potential for usage of solar energy in Sarajevo (around $1350 \mathrm{kWh} / \mathrm{m}^{2}$ per year on a horizontal surface). The total amount of solar irradiance is about $5-10 \%$ larger than in the south of Germany (the majority of solar energy utilising facilities is located in the south), and about the same as in the north of Spain. However, in spite of a larger solar energy potential than Germany, Bosnia and Herzegovina is falling massively behind in the usage of solar energy compared to Germany with only 0,27\% of electricity being produced from solar energy. These figures show that there is a lot of unused solar potential especially in the area of the city of Sarajevo, but also in the entire country.

The study also shows that the relative energy loss on panels set at a fixed tilt angle between $24^{\circ}$ and $33^{\circ}$ compared to the panels set at the optimum tilt angle which is changed every month does not exceed $4 \%$, which shows that there is no actual need to invest in much more expensive one axis solar tracking modules, when we are talking about small solar electricity or heat producing systems. This paper did not take into consideration two axis tracking solar modules.

Taking into consideration that the city of Sarajevo is almost totally dependant on energy imports, extensive usage of solar energy is a great way to improve the cities energy situation. Perhaps this dependency is not so important and visible when looking at the electrical energy needs, but when it comes to heat energy needs it becomes apparent. Most of the cities' heating needs come from natural gas, while other big sources are coal and wood biomass. All of these energy sources have very negative effects on the city. Even though natural gas does not contribute to a substantial air pollution in the winter it is quite expensive and the city is dependant on gas imports from Russia, which is a hazard because it can lose its main source of heat energy unexpectedly due to various reasons. On the other hand, the usage of locally produced coal and wood biomass poses a great health hazard, because it increases the already high and dangerous levels of air 
pollution in the city in the winter months. The utilisation of solar energy might be one of the solutions to both problems at the same time, it is a clean renewable energy source and with the development of heat energy storage technologies it shows the potential to solve these issues. Its utilisation would require a substantial initial investment, but afterwards it would pay itself of since it is virtually free energy. In order to further promote this idea, more accurate data about solar energy potential in the city needs to be acquired in further research.

In order to get more accurate data, extensive measurements of a wide range of parameters should be conducted in various places in the city. To increase accuracy, alongside global horizontal irradiance, diffuse horizontal irradiance, direct normal irradiance and the surface reflectance factor should be measured as well. This data, when obtained, besides from giving a more accurate assessment of the solar energy potential in the city, could also help the development of more accurate mathematical models for assessing the solar energy potential.

\section{Acknowledgements}

Some of the input data used in this paper were obtained from the NASA Langley Research Center (LaRC) POWER Project funded through the NASA Earth Science/Applied Science Program. Some of the input data used in this paper were generated using Copernicus Atmosphere Monitoring Service Information (2019). Some of the input data were obtained from National Oceanic and Atmospheric Administration (NOAA). This paper is realized in framework of project supported by the Ministry of Education, Science and Youth of Sarajevo Canton.

\section{References}

[1] https://www.cin.ba/energopotencijal/energopotencijal.pdf. Accessed on: 2019-04-07

[2] http://toplanesarajevo.ba/docs/osnovni_podaci_toplane.pdf. Accessed on: 2019-04-07

[3] https://www.kvalitetzraka.ba/uploads/files/1507118924-9363699.pdf. Accessed on: 2019-04-07

[4] Kumar, A.; Shukla, S. K. (2018). Solar thermal energy storage, Centre for Energy and Resource Development, Department of Mechanical Engineering, Indian Institute of Technology (BHU), Varanasi, India

[5] https://power.larc.nasa.gov/. Accessed on: 2019-03-22

[6] https://www.ngdc.noaa.gov/geomag/calculators/magcalc.shtml\#declination. Accessed on: 2019-03-29

[7] http://www.soda-pro.com/web-services/radiation/cams-radiation-service. Accessed on: 2019-03-23

[8] https://www.irena.org/-/media/Files/IRENA/Agency/Publication/2018/Jul/IRENA_Renewable_Energy_

Statistics_2018.pdf. Accessed on: 2019-04-07

[9] Akcioni plan za korištenje obnovljive enrgije u Bosni i Hercegovini (2016). Ministry of Foreign Trade and Economic Relations of Bosnia and Herzegovina

[10] Hadziahmetovic, H[alima]; Dzaferovic, E[jub]; Ahmovic, I[smira] \& Blazevic, R[ejhana] (2018). Analysis of Wind Velocity Data in the Area of the City of Sarajevo in Period from 2001-2010, Proceedings of the 29th DAAAM International Symposium, pp.0250-0259 B. Katalinic (Ed.), Published by DAAAM International, ISBN 978-3-902734-20-4, ISSN $\quad$ 1726-9679, $\quad$ Vienna, Austria DOI: $10.2507 / 29$ th.daaam.proceedings.036

[11] Suh, J.; Choi, Y. (2017). Methods for Converting Monthly Total Irradiance Data into Hourly Data to Estimate Electric Power Production from Photovoltaic Systems: A Comparative Study, Available from: https://www.mdpi.com/2071-1050/9/7/1234/htm Accessed on: 2019-04-09

[12] Collares-Pereira, M.; Rabl, A. (1979). The Average Distribution of Solar Radiation - Correlations between Diffuse and Hemispherical and between Daily and Hourly Insolation Values. Solar Energy, Vol., 22., (February 1979) 155$164,0038-092 X / 79 / 0201-0155 / 79 / \$ 02.00 / 0$

[13] http://www.powerfromthesun.net/Book/chapter03/chapter03.html. Accessed on: 2019-04-09

[14] Duffie, J.; Beckman, W (2005). Solar Engineering of Thermal Processes, John Wiley \& Sons, Inc, ISBN 978-0-47169867-8, Hoboken, New Jersey, USA

[15] Khatib, T.; Elmenreich, W. (2015). “A Model for Hourly Solar Radiation Data Generation from Daily Solar Radiation Data Using a Generalized Regression Artificial Neural Network", International Journal of Photoenergy, Volume 2015, Article ID 968024, 13 pages, DOI http://dx.doi.org/10.1155/2015/968024

[16] Hyung-Jin, L.; Shin-Young, K.; Chang-Yeol, Y. (2017). Comparison of Solar Radiation Models to Estimate Direct Normal Irradiance for Korea, Available from: https://www.mdpi.com/1996-1073/10/5/594/htm Accessed: 201904-11

[17] Maxwell, E. (1987). A Quasi-Physical Model for Converting Hourly Global Horizontal to Direct Normal Insolation, Solar Energy Research Institute, Midwest Research Institute, Golden, Colorado, USA

[18] https://gssc.esa.int/navipedia/index.php/Two-body_Problem Accessed on: 2019-04-11

[19] Murison, M. (2006). A Practical Method for Solving the Kepler Equation, Available from: http://www.alpheratz.net/murison/dynamics/twobody/KeplerIterations summary.pdf Accessed: 2019-04-11

[20] https://solargis.com/maps-and-gis-data/overview/ Accessed on: 2019-04-18

[21] https://www.ise.fraunhofer.de/de/presse-und-medien/news/2018/stromerzeugung-in-deutschland-2017-solar-undwindenergie-uebertreffen-erstmals-kohle-und-kernenergie.html Accessed on: 2019-04-18 